\title{
Conflict of Interest in Cardiovascular Publications
}

\author{
Joseph S. Alpert, MD \\ Editor-in-Chief
}

The editors of all cardiovascular journals in North America and Europe meet each year at the annual scientific sessions of the American Heart Association and the American College of Cardiology. We discuss a variety of issues of shared concern. Recently, we have been discussing disclosure of potential conflict of interest, particularly financial disclosures. The following statement was adopted by the editors as reflecting the strongly held opinions of the group. These guidelines will be published in all cardiovascular journals over the next year and will be implemented thereafter. The guidelines were written by a subcommittee of the Heart Editors Action Round Table consisting of the following members: Seymour Furman, MD (Chairman), Joseph S. Alpert, MD, Jay N. Cohn, MD, and Gerald C. Timmis, MD.

Cardiology will implement these guidelines immediately.

\section{Managing Potential Conflict of Interest during Publication and Presentation}

We live in an era of extensive industrial support and involvement in medical research. The National Institutes of Health undertakes cooperative endeavors in which industry provides substantial support in money or in kind, without which the research of clinical effort could not be undertaken. Industry additionally provides substantial nongovernmental clinical and research support to individuals and medical institutions. The present state of health care in the United States is the result of the interaction between the profession, government and industry. During the most recent annual scientific sessions of major cardiologic societies, the large majority of invited participants declared a potential conflict of interest, a small number were employees of industry. Principal investigators receiving substantial support from industry are likely to be the most expert in those fields, which they are studying and developing and about which they will write research and review articles. An author-investigator uninvolved with industry that supports or develops medication, manufactures devices or provides services may be significantly less knowledgeable than one not so involved. Given these circumstances, the medical profession must be made aware of individual involvements that may influence interpretations reported in oral or written presentations.

Bias in presentation of data and opinion may be affected by strongly held scientific and medical opinion, but may also be based on financial considerations. Given these realities, the potential for conflict of interest, based on influences other than scientific and medical, is substantial and as it may be unavoidable, must be declared. Such declaration must not be construed as an implication

\section{KARGER}

Fax + 41613061234

E-Mail karger@karger.ch

www.karger.com

(C) 2001 S. Karger AG, Basel

0008-6312/01/0952-0053\$17.50/0

Accessible online at:

www. karger.com/journals/crd
} 
of impropriety that prejudices the author or program participant. The disclosure(s) should include potential conflict of interest relationships of the author or those close to him or her either in family or institution relative to any organization whose products or services are being discussed or affected by the oral or written presentation.

Financial relationship is defined by ownership of patent, equity, options or obligations, or receipt of more than minimal goods, services, or cash within, for example, two years. Research support should always be declared whether from a non-profit or governmental agency or from a For Profit Organization, revenue received as part of a multicenter trial in which the investigator has no role other than relating to her/his patients and if less than $1 \%$ of the total trial expenditure and consumption of comestibles and receipt of disposables, need not be declared.
Declaration of potential conflict of interest should be part of each publication or presentation and be designated as one or more of four categories: (1) No relationship. (2) Relationship with a For Profit Organization, as defined above. (3) Research relationship with a For Profit or Not For Profit Organization, which should be named. (4) Employee of a For Profit or Not For Profit Organization.

Failing an author's acknowledgement and appropriate designation of the potential conflict of interest, it will be the prerogative of the journal editor or program organizer to designate the drug, device or service about which conflict may exist. The potential conflict will be listed within the author listing for all four categories for all authors. Identification of affiliation of all authors, as at present, will be included as well as sources of funding. 